\section{Psicologia Escolar \\ e Educacional}

ARTIGO

DOI: http://dx.doi.org/10.1590/2175-35392021208740

Localizador - e208740

\title{
CRIANÇAS COM DEFICIÊNCIA VISUAL E SUAS ATIVIDADES CRIADORAS: CONTRIBUIÇÕES DA PERSPECTIVA HISTÓRICO-CULTURAL
}

\begin{abstract}
Marina Teixeira Mendes de Souza $\operatorname{Costa}^{1} \mathbb{D}$; Fabrício Santos Dias de Abreu ${ }^{2} \mathbb{D}$; Daniele Nunes Henrique Silva ${ }^{2,}, \mathbb{D}$
RESUMO

A Perspectiva Histórico-Cultural tem defendido a centralidade da imaginação para o desenvolvimento infantil e a necessidade de se entender a deficiência por uma via mais positiva, social e inclusiva. Neste trabalho teóricoargumentativo nosso objetivo foi problematizar como as atividades criadoras se desenvolvem em crianças com deficiência visual. Partindo do pressuposto de que essas crianças apresentam particularidades no modo de percepção e produção de imagens e configuram formas alternativas de organização da atividade criadora, realizou-se um levantamento bibliográfico sobre a produção científica de matriz Histórico-Cultural que envolve essas temáticas entre os anos de 2007-2017, nas bases de dados da Biblioteca Digital Brasileira de Teses e Dissertações, PROQUEST e B-ON (Portugal). Identificamos que os estudos sobre essas temáticas são reduzidos, mas avançam no sentido de defenderem que as situações de brincadeira, a atividade criadora e a autoria são espaços privilegiados para as crianças com deficiência visual interagirem com o ambiente, os objetos e os pares sociais.
\end{abstract}

Palavras-chave: Imaginação infantil; deficiência visual; Psicologia Histórico-Cultural.

\section{Children with visual disabilities and their creative activities: contributions from the historical-cultural perspective}

\begin{abstract}
The Historical-Cultural Perspective has defended the centrality of imagination for child development and the need to understand disability in a more positive, social and inclusive way. In this theoretical-argumentative work, our objective was to problematize how creative activities are developed in children with visual impairment. Based on the assumption that these children have particularities in the way of perception and production of images and configure alternative forms of organization of creative activity, a bibliographic survey was carried out on the scientific production of the Historical-Cultural matrix that involves these themes between the years of 2007-2017, in the databases of the Brazilian Digital Library of Theses and Dissertations, PROQUEST and B-ON (Portugal). We identified that the studies about these themes are reduced, but they move towards defending that situations of play, creative activity and authorship are privileged spaces for children with visual impairment to interact with the environment, objects and social peers. Keywords: Children's imagination; visual impairment; Historical-Cultural Psychology.
\end{abstract}

\section{Niños con deficiencia visual y sus actividades creadoras: contribuciones de la perspectiva histórico-cultural RESUMEN}

La Perspectiva Histórico-Cultural ha defendido la centralidad de la imaginación para el desarrollo infantil y la necesidad de entenderse la deficiencia por un sendero más positivo, social e inclusiva. En ese estudio teórico-argumentativo nuestro objetivo fue problematizar cómo las actividades creadoras se desarrollan en niños con deficiencia visual. Partiéndose del presupuesto que esas presentan particularidades en el modo de percepción y producción de imágenes y configuran formas alternativas de organización de la actividad creadora, se realizó una recopilación bibliográfica sobre la producción científica de matriz Histórico-Cultural que abarcan esas temáticas entre los años de 2007-2017, en las bases de datos da Biblioteca Digital Brasileña de Tesis y Tesinas, PROQUEST y B-ON (Portugal). Identificamos que los estudios que abarcan esas temáticas son escasos, pero avanzan en el sentido de defender que las situaciones de juegos, la actividad creadora y la autoría son espacios privilegiados para los niños con deficiencia visual interactuar con el ambiente, los objetos y los pares sociales.

Palabras clave: Imaginación infantil; deficiencia visual; Psicología Histórico-Cultural.

\footnotetext{
${ }^{1}$ Secretaria de Estado de Educação do Distrito Federal - Brasília - DF - Brasil; mtmscosta@gmail.com

${ }^{2}$ Universidade de Brasília - Brasília - DF - Brasil; fabra201@gmail.com

${ }^{3}$ Universidade Estadual de Campinas/UNICAMP - Campinas - SP - Brasil; daninunes74@gmail.com
} 


\section{INTRODUÇÃO}

$\mathrm{O}$ ato de imaginar e criar é complexo e específico do gênero humano. As capacidades de perceber o ambiente e criar intencionalmente estratégias para sobrevivência - deslocadas do campo perceptivo concreto - caracterizam a imaginação. Embora seja um termo usado de forma corriqueira, o conceito de imaginação revela diferenças em seu modo de ser compreendido, tanto na história quanto na própria Psicologia (Vigotski, 2009; Silva, 2012).

Para L. S. Vigotski (1896-1934), precursor da Perspectiva Histórico-Cultural, a imaginação envolvia uma atividade reconstituidora ou reprodutiva e combinatória ou criadora. A dimensão reconstituidora - ou reprodutiva [? relaciona-se diretamente com a memória e se baseia na reprodução de meios de condutas já elaborados e que nos remetem às impressões passadas. Há uma relação entre a memória e a imaginação, sem dúvida, pois o cérebro humano conserva a experiência vivida, o que favorece a reprodução de ações aprendidas. $O$ segundo tipo de atividade, denominada combinatória ou criadora, refere-se à criação de novas imagens ou ações que se distanciam da reprodução. Ainda que o cérebro conserve a experiência, ele a reelabora e a recombina articulada aos elementos da realidade, promovendo a emergência de novos padrões comportamentais, novas situações, ações, sentimentos e objetos. O homem é capaz, portanto, não somente de guardar experiências e reproduzi-las, mas, a partir delas, criar novas maneiras de pensar e agir. Ou seja, não repetimos o vivido, mas por meio da imaginação planejamos o futuro, transformamos o presente e reconstruímos o passado (Vigotski, 2009).

Do ponto de vista ontogenético, isso implica afirmar que a imaginação é a base fundamental para a atividade criadora, articulando-se aos aspectos culturais mais amplos da experiência humana, seja na arte, na ciência ou na técnica. Tudo aquilo que faz parte do acervo cultural da humanidade é produto da sua criação. Vigotski (2009) explicita que todos os artefatos culturais são frutos de uma operação simbólica complexa e historicamente demarcada. Tal operação, também advinda da própria experiência com o campo simbólico, materializa-se como imaginação cristalizada. Isto significa dizer que aquele que cria é sempre produto de um tempo histórico especifico e do meio social; sua invenção emerge das necessidades anteriores a ele e se ancora naquelas que se dirigem para além dele (Vigotski, 2009).

Vigotski (2003) chama nossa atenção para qual seria, então, a função da imaginação? Ela seria responsável pela "organização de formas de comportamento que ainda não ocorreram na experiência do ser humano? ( $p$. 153). A imaginação, nesses termos, se direciona a um porvir. Cruz (2015), inspirada pelas ideias de Vigotski, afirma que a imaginação é uma complexa atividade psíquica que dá origem ao que denominamos por sistema psicológico; responsável pela emergência do sistema funcional.
Para formas tão complexas de atividade, que vão além dos limites dos processos aos quais, costumeiramente, chamamos de funções, seria correto utilizar a denominação de sistema psicológico, haja vista a sua complicada estrutura funcional. São características desse sistema o predomínio das conexões e relações interfuncionais (Vigotski, 2001, p. 436).

Corroborando com esse pensamento, Cruz (2011) discute sobre a necessidade de se estudar a relação entre a imaginação, a linguagem e a cognição no processo de elaboração do conhecimento, tendo como premissa que essas relações se modificam durante o desenvolvimento. Elas são dinâmicas e variam também conforme os diferentes ?modos de elaboração do conhecimento e da atividade criativa? (Cruz, 2011, p. 94) na ontogênese e assumem contornos específicos, principalmente, na infância.

Nessa linha, nosso interesse nesse trabalho teórico-argumentativo é problematizar, por meio de um apurado levantamento bibliográfico, como as atividades criadoras (brincar, narrar e desenhar) se desenvolvem em crianças que percebem e interagem com o mundo de forma diferenciada. A experiência da deficiência visual nos parece oportuna para se entender as particularidades no modo de percepção e produção de imagens que envolvem esses sujeitos, configurando formas alternativas de organização da atividade criadora, conforme abordaremos.

\section{Acompreensão da deficiência e suas potencialidades}

Vigotski (2012), já no início do século XX, critica as limitadas concepções sobre o desenvolvimento da pessoa com peculiaridades no desenvolvimento. Para ele, as leis gerais do desenvolvimento são as mesmas para toda e qualquer criança, mesmo as com deficiência, sendo apenas distintas do ponto de vista qualitativo e, portanto, mediacional.

$\mathrm{Na}$ época, o teórico bielorusso repreendeu os estudos centrados em compreender o desenvolvimento apenas pelo aspecto quantitativo, pois alguns métodos clássicos somente mensuravam o grau da deficiência, contudo, não a explicavam. Na contramão dessas abordagens, ele buscava investigar o modo como se dava a organização do funcionamento psíquico nessa condição e as potencialidades do desenvolvimento, por uma via de entendimento muito mais positiva, social e inclusiva 
(Nuemberg, 2008).

Para Vigotski (2012), a deficiência desenvolve-se em dois níveis: primário e secundário. 0 primeiro refere-se ao aspecto orgânico, fisiológico. $O$ secundário diz respeito à forma como culturalmente a deficiência é significada. A deficiência secundária vincula-se diretamente ao meio sócio-histórico em que ela é vivenciada. De fato, os órgãos dos sentidos se caracterizam como biológicos, porém constituem-se como órgãos sociais, uma vez que a suas capacidades de percepção se entrelaçam às experiências humanas vivenciadas (Barroco, 2007).

Nuemberg (2008) esclarece que as limitações enfrentadas pela pessoa com deficiência são de ordem também social, pois o mundo está organizado para aquilo que é entendido como padrão de normalidade. A sociedade está voltada para um perfil de desenvolvimento humano hegemônico, o que, consequentemente, gera obstáculos para a participação efetiva da pessoa com deficiência na sociedade.

Para Vigotski (2012), em se tratando da cegueira, ela não se resume apenas a uma ausência do sentido da visão; ela reconfigura as potencialidades da pessoa. Assim, a cegueira gera novas estratégias para o funcionamento do sistema psíquico, transformando o funcionamento habitual. Ou seja, paradoxalmente, a cegueira é fonte de manifestação de habilidades, competências e força.

Sendo assim, Vigotski (2012) alerta que a pessoa cega não está submersa na escuridão, como se pensa. Para ele, não se pode compará-la com uma pessoa vidente de olhos vendados, pois ela experimenta outra forma de visualidade e seu funcionamento psíquico se configura de outro modo.

Assumindo a vanguarda do que hoje se entende por inclusão, Vigotski adverte que a compreensão da cegueira na ciência moderna deve se fundamentar em três eixos, quais sejam: a) a prevenção da cegueira orientada às massas populares; $b$ ) a eliminação da educação dos cegos pautada no isolamento e na invalidez; e c) o trabalho social das pessoas cegas. Ele pontua que o trabalho, aqui, não se refere à filantropia ou assistencialismo, mas "à autêntica essência do trabalho, a única capaz de criar para a personalidade a necessária posição social" (Vigotski, 2012, p. 113, tradução nossa).

Essas três dimensões são centrais porque as pessoas cegas precisam superar o sentimento social de inferioridade, o que envolve "um processo (orgânico e psicológico) de criação e recriação da personalidade da criança" (Vigotski, 2012, pp.16-17) que não é de ordem individual, mas essencialmente relacional. Isso implica afirmar que a mediação adequada e os recursos apropriados utilizados com a criança com deficiência no âmbito escolar e clínico, por exemplo, impactam diretamente sua trajetória desenvolvimental.

A seguir, discutiremos as singularidades da deficiência visual e as especificidades do funcionamento imaginativo que envolvem o brincar, narrar e desenhar das crianças em evidência, a partir de pesquisas realizadas nos últimos dez anos que assumem a perspectiva histórico-cultural como matriz teórica.

As atividades criadoras da criança com deficiência visual: contribuições dos estudos desenvolvidos a partir da perspectiva histórico-cultural

$O$ ato de enxergar, por mais orgânico que pareça, também se vincula às raízes culturais em que o indivíduo está imerso. Ao nascer, a criança percebe a luz de forma instável, difusa. À medida que cresce, a visão se desenvolve, exigindo um aprendizado e interação com o meio. Isso significa dizer que a criança, então, aprende a ver. "As pessoas não nascem sabendo ver, elas aprendem a ver desenvolvendo as estruturas dos olhos e do córtex visual" (Lima, 2006, p. 73).

Lima (2006) afirma que $75 \%$ da percepção são de responsabilidade da visão, sendo a audição, o olfato, o paladar e o tato outros modos de percepção desenvolvidos. As deficiências sensoriais, então, surgem quando há alguma alteração em um dos órgãos dos sentidos, mais especificamente, na visão e/ou na audição.

A amostra do Censo Demográfico do Instituto Brasileiro de Geografia e Estatística [IBGE] (2010) revela que, entre as deficiências no Brasil, a visual apresenta a maior taxa de incidência, representando $18,8 \%$ da população. Cabe ressaltar que existe uma gama de especificidades para designar o termo. A delimitação do grupamento de cegos e de baixa visão ou visão subnormal, por exemplo, refere-se à acuidade visual (se mede o que se percebe a uma determinada distância) e ao campo visual (amplitude da área alcançada pela visão) (Conde, 2005; Lima, 2006; Sá, Campos, \& Silva, 2007; Raposo \& Carvalho, 2015).

No caso da deficiência visual, com base na Organização Mundial da Saúde, Conde (2005) esclarece que não há um conceito absoluto, pois existem vários graus de visão residual. A cegueira total refere-se àquela em que não há qualquer percepção de luz, e a cegueira legal está especificada no Decreto no 5.296 , de 2 de dezembro de 2004 (que regulamenta o atendimento prioritário para as pessoas com deficiência):

Deficiência visual: cegueira, na qual a acuidade visual é igual ou menor que 0,05 no melhor olho, com a melhor correção óptica; a baixa visão, que significa acuidade visual entre 0,3 e 0,05 no melhor olho, com a melhor correção óptica; os casos nos quais a somatória da medida do campo visual em ambos os olhos for 
igual ou menor que $60^{\circ}$; ou a ocorrência simultânea de quaisquer das condições anteriores (Art. 5으, parágrafo 1o, inciso I, alínea c).

Lima (2006) problematiza que a grande incidência da deficiência visual se evidencia nas camadas populares, em que as condições de vida são precárias. As pesquisas (Albuquerque \& Alves, 2003; Carlos et al., 2009; Santos, Velarde, \& Ferreira, 2010; Anjos, 2013) indicam a falta de cuidados pré-natal, natal e pós-natal, de vitamina A, de condições básicas de alimentação das gestantes, doenças infectocontagiosas, tumores, glaucoma, catarata, diabetes mellitus etc. como alguns dos fatores responsáveis por problemas de visão.

Entretanto, das crianças legalmente designadas como cegas, segundo as referências descritas no decreto apresentado anteriormente, $70 \%$ delas apresentam algum uso prático da visão. Por essa razão, no âmbito educacional e assistencial, o laudo de cegueira apresentado não é suficiente para a compreensão daquilo que a criança, de fato, enxerga. Dessa maneira, é necessária a realização de uma avaliação funcional da visão para que as mediações tanto na família quanto na escola [? contextos de maior socialização infantil ? sejam eficazes para o desenvolvimento da criança, de modo a potencializar a visão residual (Sá et al., 2007).

Dessa maneira, pesquisar sobre como se desenvolvem os processos criadores das crianças cegas ou com baixa visão implica reconhecer suas particularidades e modos de imaginar e criar que, muitas vezes, podem se diferenciar do padrão estabelecido como normal ou único.

Nesse sentido, realizamos um levantamento bibliográfico de âmbito nacional (artigos, teses e dissertações) e internacional (artigos) sobre a produção científica na temática da deficiência visual e a imaginação, especificamente no que tange às atividades criadoras infantis de brincar, narrar e desenhar no período da última década - entre os anos de 2007 e 2017. As bases de dados utilizadas foram: a Biblioteca Digital Brasileira de Teses e Dissertações, PROQUEST e B-ON (Portugal).

Inicialmente, a fim de se ter um panorama geral sobre o quadro das pesquisas em deficiência visual, utilizamos os seguintes descritores ${ }^{1}$, os quais nos orientaram acerca do trabalho desenvolvido: a) deficiência visual: 717 trabalhos - 550 dissertações/167 teses; b) cegueira: 333 trabalhos - 231 dissertações/102 teses; e c) baixa visão: 526 trabalhos - 399 dissertações/127 teses.

Salientamos, contudo, que apesar de deficiência visual ser um termo mais abrangente do que cegueira

\footnotetext{
${ }^{1}$ Os descritores foram pesquisados nos seguintes idiomas: português, inglês e espanhol.
}

e baixa visão, o número de estudos encontrados com o descritor deficiência visual (717) não corresponde à soma das investigações desenvolvidas (859) com os descritores cegueira (333) e baixa visão (526). Isso nos leva a inferir que, apesar de termos muito próximos, não necessariamente foi contemplado o tema da deficiência visual. Até mesmo porque o termo cegueira, por exemplo, pode ser usado na área de Letras em seu sentido metafórico.

De qualquer forma, avaliando o número de pesquisas encontradas com o descritor deficiência visual, percebemos que, em média, foram realizadas 71 pesquisas por ano, uma quantidade considerável, que revela o interesse e a preocupação com a temática. Podemos observar que houve uma maior quantidade de produção entre as dissertações do que nas teses.

Outro ponto que nos chama atenção refere-se ao número de trabalhos associados ao descritor baixa visão. Ele supera o termo cegueira. Ainda que não seja nosso objetivo elucidarmos o motivo dessa situação, o fato nos parece curioso. Primeiro pela surpreendente quantidade de pesquisas direcionadas à baixa visão e/ou cegueira e, segundo, àqueles que não se encontraram na interseção dos dois descritores.

Logo, para aperfeiçoarmos nossa investigação bibliográfica, apesar de compreendermos que as atividades criadoras infantis de brincar, narrar e desenhar ocorrem de forma amalgamada (Costa \& Silva, 2012; Costa, Silva, \& Souza, 2013), decidimos dividi-las em descritores distintos, a saber: a) deficiência visual/cegueira/baixa visão e brincadeira; b) deficiência visual/cegueira/baixa visão e faz de conta; c) deficiência visual/cegueira/baixa visão e jogo simbólico; d) deficiência visual/cegueira/baixa visão e desenho; e e) deficiência visual/cegueira/baixa visão e narrativa. Destacamos, a seguir, as pesquisas encontradas na área da Psicologia e da Educação que assumem a perspectiva histórico-cultural como matriz epistemológica dos estudos.

De modo geral, a imaginação e a criação ocupam lugar de destaque para o pensamento vigotskiano. Podemos perceber que há diversos estudos (Maheirie, Smolka, Strappazzon, Carvalho, \& Massaro, 2015; Schroeder \& Schroeder, 2011; Schwede \& Zanella, 2013; Silva, 2012; Silva, Costa, \& Abreu, 2015) que abordam os processos criadores e a relação desses com o desenvolvimento infantil. Para a delimitação do nosso trabalho, dedicamos atenção aos estudos que trazem contribuições especificamente para as questões relacionadas à deficiência visual e às atividades criadoras infantis, tal como abordaremos a seguir.

Silva e Batista (2007) realizaram uma pesquisa cujo objetivo pautou-se em analisar as aquisições cognitivas e imaginativas de uma criança cega com quatro anos de 
idade, a qual apresentava a hipótese de ter também a síndrome (rara) de Rodriguez, "que provoca atraso no crescimento e desenvolvimento" (p. 150). As aquisições analisadas eram referentes ao uso dos objetos de forma convencional (ou não), desenvolvimento em atividades de brincadeira e a emergência de maneiras distintas de comunicação. O estudo longitudinal, dividido em sessões individuais e coletivas, teve a duração de dois anos e foi realizado junto a um grupo de convivência, no qual a criança em destaque participava. Esse grupo era formado por outras crianças com deficiência visual e, muitas delas, com outras particularidades. Por meio da observação, videogravação e anotação das sessões foram registrados os encontros e construídos os dados.

Em um recorte da pesquisa, por meio da brincadeira, as autoras afirmaram que a participante conseguiu comunicar-se com a pesquisadora. A interação criança-objeto-adulto foi importante para a aquisição e desenvolvimento da linguagem da criança pesquisada. Outro ponto foi que a mediação do adulto também foi decisiva para que a participante interagisse com o brinquedo. Em um primeiro momento, essa interação ocorreu de forma não convencional. Todavia, quando a criança, por exemplo, recebeu um tambor, somente a partir da mediação da linguagem do adulto, o brinquedo ganhou o sentido estabelecido socialmente.

Em outro viés, em uma pesquisa bibliográfica, Silva e Costa (2011) investigaram a articulação entre a educação precoce, a deficiência visual e os brinquedos adaptados. $O$ estudo foi realizado em banco de dados científicos digitais e em livros direcionados às áreas específicas da Saúde (Oftalmologia e Neurologia, Fisioterapia), Psicologia e Educação Especial. As pesquisadoras analisaram e sintetizaram os textos lidos de forma a responder sobre duas questões: a) os critérios utilizados na escolha dos brinquedos e suas respectivas adaptações para a criança com deficiência visual; e b) o papel dos responsáveis no que tange à estimulação, inclusive com os brinquedos supracitados. Nesse trabalho, Silva e Costa (2011) ressaltam a importância de se oferecer brinquedos adequados à fase de desenvolvimento da criança com deficiência visual, pois o contrário pode lhe causar desapontamentos. Com base nos estudos e considerando a segurança das crianças, as pesquisadoras sugerem que os brinquedos apresentem características específicas, tais como: contraste nas cores, brilho, luminosidade, som, tamanhos apropriados etc. Para elas, essas particularidades orientam o olhar e potencializam a acuidade visual.

Além disso, baseadas em suas próprias experiências, somadas ao levantamento bibliográfico realizado, as autoras inferem alguns aspectos importantes, a saber: a) os brinquedos adaptados são algumas das estratégias efetivas para o desenvolvimento da visão residual, da mobilidade e de outros comportamentos da criança com deficiência visual; b) a estimulação propicia benefícios contundentes quando os pais e a criança demonstram interesse em iniciar e manter essa atividade; e c) junto à estimulação adequada, é necessário integrá-la a um projeto de acessibilidades que se inicia na própria família (Silva \& Costa, 2011).

Nessa perspectiva, Ruiz e Batista $(2011,2014)$ desenvolveram um estudo com crianças cegas ou com baixa visão no intuito de compreender as interações sociais por elas realizadas e a participação do adulto nesse processo. Para tanto, essas interações foram observadas e videogravadas a partir de brincadeiras e brinquedos adequados disponibilizados para os participantes. De acordo com as autoras, a brincadeira pode ser compreendida como um espaço impulsionador para que a interação entre as crianças com deficiência visual ocorra, sendo flexível e dinâmico o modo de participação da criança. A atuação do adulto foi também crucial em diferentes momentos da composição do faz de conta, em especial, por meio da escolha e descrição dos materiais adequados e o papel que ele pode assumir na própria brincadeira. Essa conclusão caminha na mesma direção da pesquisa apresentada anteriormente (Silva \& Batista, 2007).

Mattos (2011, 2015) focaliza a imagem fotográfica como mediadora de suas pesquisas em crianças com deficiência visual. Em ambos os trabalhos, ela propôs que a investigação com crianças/jovens (com e sem deficiência visual) acontecesse por meio da fotografia. Mattos (2011) busca tensionar os diferentes olhares que as crianças apresentavam sobre os contextos em que viviam por meio das imagens fotográficas por elas realizadas. Dessa maneira, foi desenvolvida inicialmente uma oficina estética com duração de cinco encontros. Mattos (2011) explica que nas diferentes atividades realizadas durante a oficina estética - por meio das brincadeiras, da musicalidade, do alongamento do corpo, do contato com texturas e sons variados, das peças teatrais, do ato de fotografar em si etc. - foi possível "(re)inventar o sentir, o ouvir e o ver" (p. 84). Após as crianças participarem de experiências diversas, cada uma delas recebeu uma máquina fotográfica descartável para ser levada para casa para que elas produzissem suas imagens sobre os contextos em que viviam.

De maneira geral, segundo Mattos (2011), as fotografias produzidas pelas crianças revelaram os diferentes modos de ver, apresentando algumas características em comum. Por exemplo, foram retratadas imagens de familiares, brinquedos, lugares internos do lugar onde moravam, figuras representando aspectos sonoros, como televisão, cachorro latindo etc., ou, ainda, locais 
em que o sentido do olfato também compunha a fotografia como, jardim, plantas, flores etc.

Em estudo posterior, Mattos (2015), ao invés de centrar a análise na fotografia em si, analisa o processo de fotografar e produzir a imagem. Ou seja, tudo aquilo que envolvia a escolha ou não, do que e como produzir as fotografias. No seu estudo, a pesquisadora realizou uma oficina estética dividida em encontros distintos, nos quais propunha aos participantes que andassem em trajetos que simulavam espaços das cidades e, posteriormente, que produzissem narrativas fotográficas e audiovisuais.

De maneira sucinta, dada a riqueza do trabalho, em seus resultados, a pesquisadora demonstra que, a partir da mediação do outro, a produção das narrativas colaborou para o alargamento e constituição dos diferentes olhares e sentidos dos participantes envolvidos. Segundo Mattos (2015), as crianças/jovens realizaram algumas fotografias percebendo o ambiente por meio do tato, bem como, a partir do olhar do outro, por meio da linguagem.

Por último, Albarran, Cruz e Silva (2016) em um artigo teórico sobre o brincar da criança cega ou com baixa visão, apontam a importância dessa atividade para o desenvolvimento infantil em diferentes correntes teóricas na Psicologia. Em uma revisão de literatura na base de dados integrada da Universidade de Brasília, no Distrito Federal, e no oasisbr, as autoras destacam as pesquisas fundamentadas na perspectiva histórico-cultural desenvolvidas no Brasil durante o período de 2004-2014.

Nesse intervalo, verificaram que os estudos de base histórico-cultural apontam para a relevância da mediação do adulto na brincadeira da criança com deficiência visual, além da importância do faz de conta para as questões que versam sobre a mobilidade e orientação. Segundo as autoras, os trabalhos indicam, ainda, o brincar como propulsor da interação social, na medida em que promove a compreensão das regras e da cultura. Além disso, conforme o estudo aponta, o brincar pode ser lócus para o desenvolvimento da imaginação, uma vez que implica na elaboração de cenários, assunção de papéis e demais elementos que compõem a brincadeira (Albarran et al., 2016).

Outros trabalhos, como os de Celeste (2007), Sieiro (2013), Medeiros (2013), Ferroni e Gil (2012) e Freitas e Gil (2012), apesar de não se filiarem a Perspectiva Histórico-Cultural, revelam também os esforços trilhados para a compreensão das questões relacionadas ao desenvolvimento da criança com deficiência visual. Em relação ao processo imaginativo e criador, mais especificamente sobre as atividades criadoras infantis, percebemos o brincar ocupando lugar de destaque entre os trabalhos encontrados. Notamos que, apesar dos estudos não apresentarem como objetivo central as questões que circunscrevem a atividade do brincar, em certa medida ela emergiu como lócus para que as pesquisas se desenvolvessem. As situações de faz de conta, livres ou estruturadas foram escolhidas para serem observadas a fim de se estudar a criança com deficiência visual e os seus processos de desenvolvimento das habilidades sociais (Celeste, 2007), os seus modos de interação (Freitas \& Gil, 2012), as formas de mediação social da aprendizagem (Ferroni \& Gil, 2012), o seu desenvolvimento linguístico (Medeiros, 2013) e a sua constituição subjetiva (Sieiro, 2013).

Sobre as investigações realizadas ancoradas na perspectiva histórico-cultural (Albarran et al., 2016; Mattos, 2011, 2015; Ruiz \& Batista, 2011, 2014; Silva \& Costa, 2011; Silva \& Batista, 2007) nos deparamos com os esforços conceituais e empíricos de pesquisadores que buscaram entender a dinâmica das atividades criadoras infantis a partir das especificidades da deficiência visual. Esses estudos apesar de serem quantitativamente poucos para o recorte temporal de dez anos, avançam no sentido de defenderem que as situações de brincadeira, a atividade criadora e a autoria são espaços privilegiados para as crianças com deficiência visual interagirem com o ambiente, os objetos e os pares sociais, em que a imaginação assume centralidade para o desenvolvimento infantil.

Ademais, esses trabalhos asseveram a importância da participação do adulto no faz de conta da criança cega ou com baixa visão, no que tange ao desenvolvimento da linguagem, à apreensão de regras sociais estabelecidas historicamente e aos materiais adequados a serem escolhidos para a atividade. Sobre essa adequação, Silva e Costa (2011) são categóricas em frisar a participação da família em estimular a criança desde cedo em um projeto de acessibilidades no próprio ambiente familiar. Isso implica afirmar que, para essa matriz teórica, o brincar está intrinsecamente relacionado ao desenvolvimento dos sistemas psicológicos tipicamente humanos e que, no caso das crianças com deficiência visual, é relevante estar atento às mediações e aos brinquedos utilizados, a fim de garantir ampla participação na brincadeira, potencializando o desenvolvimento das atividades criadoras e a emergência de rotas alternativas de desenvolvimento.

Apontamos também que Mattos (2011, 2015), ao trabalhar a fotografia com crianças com e sem deficiência visual, nos mostra que as imagens fotográficas são construídas para além do sentido da visão. Outras percepções como o olfato, o tato e a audição compõem o plano imaginativo e criador das crianças com deficiência visual, revelando, segundo a pesquisadora, outros 
modos de ver e sentir as imagens. Além disso, as fotografias infantis e as narrativas sobre elas se materializam enquanto expressões da autoria-criação impregnadas pelos afetos compartilhados entre os participantes.

\section{CONCLUSÃO}

Ao longo desse texto trouxemos as contribuições da perspectiva histórico-cultural, principalmente dos textos clássicos de Vigotski, para se entender a centralidade dos processos imaginativos no funcionamento psíquicos daqueles sujeitos que apreendem, sentem e interagem com o mundo por vias que não-hegemônicas, pois possuem deficiência visual.

Nosso objetivo foi de realizar um levantamento das pesquisas realizadas nos últimos dez anos, tecendo diálogos teóricos entre as investigações e demostrando os avanços conquistados. Contudo, lamentamos a escassez de trabalhos nessa temática.

Até aqui, pelo que conseguimos identificar, todas as pesquisas focalizadas revelam as peculiaridades na forma como essas crianças interagem com o mundo, trazendo indícios sobre uma mudança qualitativa na forma de organização da atividade criadora (brincar, narrar e desenhar, por exemplo), em razão das relações entre a percepção, a produção de imagem e a imaginação. Isso traz contribuições centrais para o planejamento de ações educativas e clínicas, bem como para a elaboração de políticas, currículos e intervenções que potencializem o desenvolvimento das crianças com deficiência visual.

\section{REFERÊNCIAS}

Albarran, P. A. O.; Cruz, E. A. P. S.; Silva, D. N. H. (2016). Crianças com cegueira e baixa visão: o brincar na perspectiva histórico-cultural. Psicologia em Estudo, 21(2), 199-210. https://doi.org/10.4025/psicolestud.v21i2.27860

Albuquerque, R. C.; Alves, J. G. B. (2003). Afecções oculares prevalentes em crianças de baixa renda atendidas em um serviço oftalmológico na cidade do Recife-PE, Brasil. Arquivos Brasileiros de Oftalmologia, 66(6), 831-834. https://doi.org/10.1590/S0004-27492003000700017

Anjos, D. R. (2013). Atividades físicas e esportivas para pessoas com deficiências visuais. In E. Ferreira (Eds.), Educação Física Inclusiva, volume 7, (p. 119-143) Juiz de Fora: NGIME/UFJF.

Barroco, S. M. S. (2007). A educação especial do novo homem soviético e a psicologia de L. S. Vigotski: implicações e contribuições para a psicologia e a educação atuais. (Tese de Doutorado). Universidade Estadual Paulista, São Paulo.

Carlos, G. A.; Schellini, S. A.; Espíndola, R. F.; Lana, F. PP.; Rodrigues, A. C. L.; Padovani, C. R. (2009). Prevalência de catarata na região Centro-Oeste do estado de São Paulo, Brasil. Arquivos Brasileiros de Oftalmologia, 72(3), 375379. https://doi.org/10.1590/S0004-27492009000300018
Celeste, M. (2007). Social skills intervention for a child who is blind. Journal of Visual Impairment \& Blindness, 101(9), 521-533.

Conde, A. J. M. (2005). Definindo a cegueira e a visão subnormal. Instituto Benjamin Constant, Rio de Janeiro. Recuperado de http://ibcserver0c.ibc.gov.br/index. php?blogid=1\&query=cegueira

Costa, M. T. M. S.; Silva, D. N. H. (2012). O corpo que escreve: considerações conceituais sobre a aquisição da escrita. Psicologia em Estudo [online], 17(1), 55-62. http://dx.doi. org/10.1590/S1413-73722012000100007.

Costa, M. T. M. S.; Silva, D. N. H.; Souza, F. F. (2013). Corpo, atividades criadoras e letramento. São Paulo: Summus Editorial.

Cruz, M. N. (2011). Imaginação, linguagem e elaboração de conhecimento na perspectiva da psicologia históricocultural de Vigotski. In: Smolka, A. L. B.; Nogueira, A. L. H. (Eds.), Emoção, memória, imaginação a a constituição do desenvolvimento humano na história. (pp. 85-103). Campinas, SP: Mercado de Letras.

Cruz, M. N. (2015). Imaginário, imaginação e relações sociais: reflexões sobre a imaginação como sistema psicológico. Cadernos Cedes, v.35, 361-374. https://doi.org/10.1590/ CC0101-32622015V35ESPECIAL154116

Decreto n. 5.296. (2004). Regulamenta as Leis n. 10.048, de 8 de novembro de 2000, que dá prioridade de atendimento às pessoas que especifica, e 10.098, de 19 de dezembro de 2000, que estabelece normas gerais e critérios básicos para a promoção da acessibilidade das pessoas portadoras de deficiência ou com mobilidade reduzida, e dá outras providências. Brasil: Presidência da República. Disponível em: http://www.planalto.gov.br/ccivil_03/_ato20042006/2004/decreto/d5296.htm

Ferroni, G. M.; Gil, M. S. C. A. (2012). A importância da mediação do adulto na brincadeira de uma criança cega. Rev. Ibero-Americana de Estudos em Educação, 7(3), 62-72. https://doi.org/10.21723/riaee.v7i3.5634

Freitas, M. L.; Gil, M. S. A. (2012). Interação social de crianças cegas e de crianças videntes na educação infantil. Psicologia Escolar e Educacional. 16(2), Julho/Dezembro, 317-327.

Instituto Brasileiro de Geografia e Estatística. (2010). CENSO 2010. Disponível em: https://censo2010.ibge.gov.br/ resultados.html

Lima, P. A. (2006). Educação inclusiva e igualdade social. São Paulo: Avercamp.

Maheirie, K.; Smolka, A. L. B.; Strappazzon, A. L.; Carvalho, C. S.; Massaro, F. K. (2015). Imaginação e processos de criação na perspectiva histórico-cultural: análise de uma experiência. Estudos de Psicologia (Campinas) [online], 32(1), 49-61. https://doi.org/10.1590/0103-166X2015000100005.

Mattos, L. K. (2011). Sobre fotografia e (in)visibilidades: olhares de crianças com deficiência visual. (Dissertação de Mestrado). Universidade Federal de Santa Catarina, Santa Catarina. 
Mattos, L. K. (2015). Olhos abertos para ouvir, sentir, pensar: crianças com deficiência visual fotografando a cidade. (Tese de Doutorado). Universidade Federal de Santa Catarina, Santa Catarina.

Medeiros, C. S. (2013). Interação mãe-criança com deficiência visual: um estudo longitudinal das habilidades sociocomunicativas infantis. (Tese de Doutorado). Universidade Federal da Paraíba, Paraíba.

Nuernberg, A. H. (2008). Contribuições de Vigotski para a educação de pessoas com deficiência visual. Psicologia em Estudo [online], 13(2), 307-316. http://dx.doi.org/10.1590/ S1413-73722008000200013.

Raposo, P. N.; Carvalho, E. N. S. (2015). A pessoa com deficiência visual na escola. In: Maciel, D. A.; Barbato, S. (Eds.), Desenvolvimento humano, educação e inclusão escolar (pp. 157-173). 2 ed. Brasília: Editora Universidade de Brasília.

Ruiz, L. C., \& Batista, C. G. (2011). Formas de atuação do adulto na brincadeira em grupo de crianças com deficiência visual In: VI Congresso Brasileiro Multidisciplinar de Educação Especial, Londrina. Brincar, desenvolvimento e aprendizagem, p. 992-1003.

Ruiz, L. C.; Batista, C. G. (2014). Interação entre crianças com deficiência visual em grupos de brincadeira. Revista Brasileira de Educação Especial [online], 20(2), 209-222. http://dx.doi.org/10.1590/S1413-65382014000200005.

Sá, E.; Campos, I. M.; Silva, M. B. C. (2007). Formação continuada a distância de professores para o atendimento educacional especializado: deficiência visual. Brasília, DF: SEESP/SEED/MEC.

Santos, E. N.; Velarde, L. G. C.; Ferreira, V. A. (2010). Associação entre deficiência de vitamina $A$ e variáveis socioeconômicas, nutricionais e obstétricas de gestantes. Ciência \& Saúde Coletiva, 15(Suppl. 1), 1021-1030. http:// dx.doi.org/10.1590/S1413-81232010000700008

Schroeder, S. C. N.; Schroeder, J. L. (2011). Apropriação da música por crianças pequenas: mediação, sentidos musicais e valores estéticos. In: Smolka, A. L. B.; Nogueira, A. L. H. (Eds.). Emoção, memória, imaginação a a constituição do desenvolvimento humano na história. (pp. 57-83). Campinas, SP: Mercado de Letras.

Schwede, G.; Zanella, A. V. (2013). Olhares de crianças a relevar a polifonia da cidade. Psico-USF, Bragança Paulista, 18(3), 395-406, set/dez

Sieiro, A. A. (2013). Impasses na constituição subjetiva de crianças com deficiência visual congênita. (Dissertação de Mestrado). Universidade Federal de Uberlândia, Minas Gerais.

Silva, D. N. H. (2012). Imaginação, criança e escola [coleção imaginar e criar na educação infantil]. São Paulo: Summus.

Silva, D. N. H.; Costa, M.; Abreu, F. (2015). Imaginação no faz de conta: o corpo que brinca. In: Silva, D. N. H.; Abreu, F. (Eds.), Vamos brincar de quê? Cuidado e educação no desenvolvimento infantil (pp. 111-132). São Paulo: Summus.

Silva, M. A.; Batista, C. G. (2007). Mediação Semiótica: Estudo de Caso de uma Criança Cega, com Alterações no Desenvolvimento. Psicologia: Reflexão e Crítica, 20 (1), 148-156.

Silva, S. M. M.; Costa, M. P. R. (2011). Brinquedos adaptados na estimulação de crianças pequenas, com baixa visão. Boletim Academia Paulista de Psicologia, São Paulo, 31(81), 496-509.

Vigotski, L. S. (2001). Obras escogidas II. Madrid: Machado Libros.

Vigotski, L. S. (2003). Psicologia pedagógica. São Paulo: Artmed.

Vigotski, L. S. (2009). Imaginação e criação na infância. São Paulo: Ática.

Vigotski, L. S. (2012). Obras Escogidas V - Fundamentos de defectologia (J. Blank, Trad. Org.). Madrid, Machado Grupo de distribución.
Recebido: 20 de julho de 2018 Aprovado: 08 de janeiro de 2020 